\title{
Sosyal Harcamaların Ekonomik Büyüme Üzerine Etkileri: Türkiye Düzey 1 Bölgeleri için Panel Veri Analizi
}

\author{
Araştırma Makalesi /Research Article
}

\author{
Aykut BAȘOĞLU ${ }^{1}$
}

ÖZ: Bu çalışmada, kamu sosyal harcamalarının ve sosyal harcama bileşenleri olan sağllk, eğitim ve sosyal koruma harcamalarının ekonomik büyüme üzerindeki etkilerinin araştırılması amaçlanmıştır. Çalı̧̧ma Türkiye İstatistiki Bölge Birimleri Sinıflandırmasına göre Düzey 1 bölgelerini ve 2004-2018 dönemini kapsamaktadır. Çalışmada iki ayrı model tahmin edilmiş olup, değişkenler arasındaki ilișkilerin analizinde Panel ARDL Havuzlanmıș Ortalama Grup (PMG) tahmincisi kullanılmıștır. Analiz sonuçları toplam sosyal harcamalar ve sosyal harcama bileşenlerinden eğitim ve sağllk harcamalarının ekonomik büyümeyi pozitif; sosyal koruma harcamalarının ise negatif etkilediğini göstermektedir. Buna göre, kamu sosyal harcamalarının kompozisyonunun eğitim ve sağllk harcamaları lehine ve sosyal koruma harcamaları aleyhine değiştirilmesi ekonomik büyümeye katkı sağlayacaktır.

Anahtar Kelimeler: Ekonomik Büyüme, Panel Veri Analizi, Sosyal Harcamalar, Türkiye Düzey 1 Bölgeleri

JEL Kodları: C33, H50, R11

\section{The Effects of Social Expenditure on Economic Growth: A Panel Data Analysis for Regions of Level 1 in Turkey}

\begin{abstract}
This study aims to investigate the effects of public social expenditures and its components, which are health, education, and social protection expenditures, on economic growth. This study involves the period of 2004-2018 and the Level 1 regions according to the Nomenclature of Territorial Units for Statistics in Turkey. In the study, two different models were estimated and the Panel ARDL Pooled Mean Group (PMG) estimator was employed to analyze the relationships between variables. The results show that total social expenditure and among its components as education and health expenditures affect economic growth positively, but social protection expenditures affect negatively. Accordingly, changing the composition of public social expenditures in favor of education and health expenditures and against social protection expenditures will contribute to economic growth.
\end{abstract}

Keywords: Economic Growth, Panel Data Analysis, Social Expenditure, Turkey Regions of Level 1

JEL Codes: C33, H50, R11

Geliş Tarihi / Received: 21/10/2020 Kabul Tarihi / Accepted: 05/01/2021

\footnotetext{
${ }^{1}$ Dr. Öğr. Üyesi, Karadeniz Teknik Üniversitesi, İİBF. İktisat Bölümü, basoglu@ktu.edu.tr, orcid.org/0000-0002-2071-6829.
} 


\section{Giriş}

Piyasa mekanizmasının işleyişini temel alan iktisadi yaklaşımlar, liberal politika uygulamaları kapsamında kamunun ekonomideki ağırlığının mümkün olduğu kadar en aza indirilmesi savunmaktadır. Ancak sahip oldukları pozitif dışsallıklar ve sosyal faydaları dolayısıyla üretimi çoğunlukla kamu tarafından üstlenilen tam ve yarı kamusal mallar ile erdemli malların sunumunun piyasaya bırakılması sosyal sorunlar yaratabilmektedir (Görkem, 2019: 2856). Keynesyen politikalar ise kamu kesimine ekonomik hayatta önemli roller biçmiştir. Bu bağlamda kamu sektörü toplumsal ihtiyaçları karşılamak üzere, devlet olma fonksiyonundan hareketle, bazı harcamalar yapmak zorundadır. Ekonomik büyüme, piyasaların regülasyonu, istihdam yaratama gibi amaçları hedefleyen bu harcamalar zaman içerisinde, sosyal devlet ilkesinin gereği olarak eğitim, sağlık ve sosyal koruma gibi toplumsal refahı yükseltmeye ve piyasa mekanizmasının ağırlığının az olduğu alanlara yönelmiştir. Bireysel faydadan ziyade toplumsal faydayı ön planda tutan, dışsal fayda yaratan kamusal mal ve hizmetlerin sunumu için yapılan bu harcamalar sosyal harcamalar olarak nitelendirilmektedir (Koç, 2019: 67). Bu harcamalar, dezavantajlı grupların korunmasında, sosyal ve siyasi istikrarın desteklenmesinde, gelir ve firsat eşitsizliklerinin çözümünde, yaşam döngüsü boyunca tüketimin düzleştirilmesinde ve ekonomik şoklar karşısında talebin dengelenmesinde önemli roller oynamaktadır. Bunlara ilave olarak son y1llarda sosyal harcamalar, sürdürülebilir kalkınma hedefleri doğrultusunda kapsayıc1 büyümenin desteklenmesi konusundaki küresel taahhüdün yerine getirilmesinde ve demografik değişimler, teknolojik gelişmeler ve iklim değişikliğinin getirdiği zorlukların giderilmesinde önemli bir politika tercihi konumuna gelmiştir (Uluslararası Çalışma Örgütü [ILO], 2017: XXIX; Uluslararası Para Fonu [IMF], 2019: 2-7).

Birçok farklı ekonomik ve sosyal amaç için yapılan sosyal harcamaların etkilerinin araştırılıp ortaya konulması, ulaşılmak istenen hedefler doğrultusunda, kamunun harcama kararlarındaki tercihleri için önem arz etmektedir. $\mathrm{Bu}$ bağlamda çalışma, kamu tarafından yapılan sosyal harcamaların ve bileşenlerinin ekonomik büyüme üzerindeki etkilerini İstatistiki Bölge Birimleri Sınıflandırmasına (IBBSS) göre Türkiye Düzey 1 bölgeleri için araştırmayı amaçlamaktadır. 2004-2018 dönemini kapsayan çalışmada panel veri analizi tekniklerinden yararlanılmıştır. Çalışma konusunun seçiminde, son yıllarda özellikle 2007-2008 küresel mali krizinden sonra, artan eşitsizlik ve yoksulluk nedeniyle savunmasız hane halklarını destekleme ihtiyacı ve sosyal harcama politikalarına olan artan ilgi belirleyici olmuştur ${ }^{2}$. Bilindiği kadarıyla çalışma sosyal harcamaları bütüncül perspektifte ele alarak Türkiye için bölgesel düzeyde yapılan öncü çalışma niteliğindedir. $\mathrm{Bu}$ bağlamda literatüre katkı sunması

\footnotetext{
${ }^{2}$ Örneğin Ekonomik Kalkınma ve İşbirliği Örgütü (OECD) ülkelerinde eğitim harcamaları hariç ortalama kamu sosyal harcamalarının GSYH'ye oranı küresel kriz öncesi 2007 yılında \%19 iken 2009-2011 yılında ortalama \%22 civarında gerçeklemiştir (OECD, 2012).
} 
beklenmektedir. Çalışma şu şekilde organize edilmiştir: giriş bölümünü takiben sosyal harcamalar ve ekonomik büyüme ilişkisinin teorik çerçevesi ele alınmış; konu ile ilgili literatürden seçilmiş çalışmalara değinilmiş; veri seti, yöntem ve bulgulara yer verilmiş ve genel değerlendirme ile çalışma sonlandırılmıştır.

\section{Sosyal Harcamalar ve Ekonomik Büyüme: Teorik Çerçeve}

Toplumsal faydayı yükseltmek için yapılan sosyal harcamalar eğitim, sağlık ve sosyal koruma harcamalarından oluşmaktadır (IMF, 2019: 8). Bu harcamalar ile çeşitli risklere maruz kalan kesimlerin toplumun diğer kesimlerden ayrışmasını önlemek, etnik ve bölgesel adaletsizlikler ile gelir dağılımı eşitsizliklerini asgari düzeye indirgemek, yoksulluğu azaltmak ve bu suretle daha katılımcı ekonomik ve siyasal sistemin desteklenmesine katkıda bulunmak hedeflenmektedir. Ayrıca, beşeri ve fiziki sermayeye ilişkin yatırımlar için elverişli bir ortam yaratarak ekonomik genişlemeyi teşvik etmek de sosyal harcamalar ile benimsenen önemli amaçlar arasında gösterilebilir (Kelly, 1997: 65).

Eğitim ve sağl1k harcamalarının büyüme üzerindeki etkilerinin temel olarak beşeri sermaye yoluyla gerçekleştiği kabul edilmektedir. Beşeri sermaye, içsel büyüme teorilerinde vurgulanan büyümenin önemli kaynaklarından biridir. İçsel büyüme modeli kamu kaynaklarının, büyümeyi destekleyen ve büyüme yaratan alanlarda kullanılmasını önermektedir. $\mathrm{Bu}$ görüşe göre sağlık harcamaları büyümeyi destekleyen, eğitim harcamaları ise büyüme yaratan harcamalardır (Kolçak ve Kalabak, 2017: 3). Toplam talebin bir bileșeni olarak cari dönemde ekonomik sonuçları olan bu harcamalar, aynı zamanda uzun dönemli yatırım harcaması niteliğindedir (Devereux ve Sabates-Wheeler, 2004: 19). Eğitim ve sağlık alanlarına yapılan harcamalar, pozitif dışsallık yaratma özelliği ile özel sektör aktivitelerinin de tamamlayıcısı olmakta ve verimlilik artışı sağlamaktadır (Castles ve Dowrick, 1990: 178; ILO, 2017: 111).

Castles ve Dowrick, (1990: 186)'e göre eğitim ve sağlık harcamaları, piyasa mekanizmasının işleyişini bozabilecek nitelikteki transfer harcamalarına nazaran ekonomik büyüme üzerinde doğrudan etki yaratma potansiyeline sahiptir. Özellikle altyapıya yönelik eğitim ve sağlık harcamaları, sermaye birikimine katkı sunarak gelir ve istihdam çoğaltanı vasıtasıyla, ekonomik büyümeyi pozitif yönde etkileyebilmektedir (Devereux ve Sabates-Wheeler, 2004: 1-2). Nitekim eğitim yoluyla gerçekleştirilen beşerî sermaye kazanımlarının işgücünün üretken kapasitesini yükseltmek; iyileştirilmiş sağlık koşullarının ise çalışma çabasını arttırmak suretiyle büyümeyi teşvik edeceği savunulmaktadır (Kelly, 1997: 64; Blankenau ve Simpson, 2004: 583). Sağlık alanında yapılacak harcamaların, ortalama yaşam beklentisini arttırarak özel sektör tasarrufları üzerinde de etkili olması muhtemeldir. Ortaya çıkabilecek böyle bir gelişme sermaye birikimi yoluyla ekonomik büyümenin gerçekleşmesine katkıda bulunabilecektir. Bu görüşlere karşın bu harcamaların, örneğin eğitim harcamalarının, büyümeye katkıda bulunan diğer faktörleri dışlaması ve ekonomide güçlü bir harcamabüyüme ilişkisinin bulunmaması gibi nedenlerle ekonomik büyüme üzerinde 
olumsuz etki yapması da söz konusu olabilmektedir (Blankenau ve Simpson, 2004: 601).

Eğitim ve sağlık harcamalarının yanı sıra bir diğer önemli sosyal harcama kalemi, sosyal koruma harcamalarıdır. Sosyal koruma harcamaları, vatandaşlara asgari bir yaşam düzeyi sağlanması, sosyal dengesizliklerin giderilmesi ve yoksulluğun azaltılması noktasında kamunun elindeki önemli politika araçlarından biridir (Solmaz ve Avc1, 2017: 56). Avrupa Bütünleştirilmiş Sosyal Koruma İstatistikleri Sistemi (ESSPROS) sosyal korumay1, bireylerin belirlenmiş risklerini veya ihtiyaç yüklerini hafifletmek amacıyla yapılan tüm müdahaleler şeklinde tanımlamaktadır. Sosyal koruma kapsamında yapılan harcamalar sekiz başlıkta sınıflandırılmaktadır. Bunlar; hastalık/sağlık bakımı, engellilik, yaşlılık, dul/yetim, aile/çocuk, işsizlik, konut ve başkaca sınıflandırılmamış sosyal dışlanma şeklindedir (Eurostat, 2016: 8). Sosyal koruma harcamaları, genellikle primli rejimin dışında kalan dezavantajlı grupları, çocukları, yaşlıları, engellileri, kadınları ve gelir güvencesinden yoksun kesimi hedeflemektedir (Altınay, 2018: 107). Sosyal koruma harcamaları, geleneksel olarak tüketimin bir parçası olarak görülmekteyken son zamanlarda, sürdürülebilir kalkınama düşüncesi çerçevesinde, kapsayıcı büyüme sürecinin ayrılmaz bir parçası ve ülke kalkınmasına yapılan yatırım olarak kabul edilmektedir (Bloom vd., 2010: 15). Bununla birlikte sosyal koruma harcamalarının ekonomik büyüme üzerindeki etkileri teorik olarak belirsizliğini korumaktadır.

Sosyal koruma harcamaları sağladıkları sosyal güvenlik ve gelirin yeniden dağıtımı fonksiyonları ile hem çalışanların moral, güven, bağlılık, iş eforu ve verimliliklerini yükseltmek hem de yapısal dönüşümünü desteklemek yoluyla iktisadi sürece olumlu katkı sağlayabilmektedir (Castles ve Dowrick, 1990: 178; Kelly, 1997: 64-65; ILO, 2017: V). Bireylerin ekonomik ve sosyal olumsuzluklara karşı korunmasında bir nevi sigorta işlevi gören (Arjona vd., 2002: 10), düşük gelirlerinin gelirlerini yükselten ve onların tüketim düzleştirmesi yapmalarına imkan veren bu harcamalar, düşük gelirlilerin 1lımlı risk almalarına ve tasarruflarını aşındırmak yerine korumalarına olanak sağlamaktadır (Furceri ve Zdzienicka, 2012: 130). Bu kapsamda ekonomik ve sosyal risklerin azaltılması ile yaşam standartları arasında var olan tamamlayıcılık ilişkisi vasıtasıyla, uzun dönemde sosyal koruma ve daha yüksek gelir arasında pozitif bir ilişki ortaya çıkmaktadır (Burgess ve Stern, 1991: 46-47). Öte yandan koruma harcamaları ile yükselen gelir, hanehalkının sağlık ve eğitim yoluyla çocuk ve genç bireylere yönelik beşeri sermaye birikimi kararlarını kolaylaştırarak ekonomik büyüme için zemin hazırlama potansiyeline sahiptir (Bloom vd., 2010, 15).

Sosyal koruma harcamalarının ekonomik büyüme üzerinde pozitif etkiler yaratabileceğini ifade eden görüşlerin yanı sıra ekonomik büyüme üzerinde negatif yönde bir etki yaratacağına yönelik teorik açıklamalarda söz konusudur. $\mathrm{Bu}$ görüşte olan yaklaşımlara göre, sosyal koruma harcamaları bu harcamalardan yararlananların yaşam boyu gelirlerinin önemli bir kısmını oluşturmakta ve bu 
kesim üzerinde refah bağımlılı̆̆ yaratarak yoksulluk kültürü doğurabilmektedir (Sawhill, 1988: 1105). Bu kültür çalışma isteğini azaltarak işsizliğe neden olabilmekte, çalışanları üretken olmaktan caydırabilmekte (Solmaz ve Avcı, 2017: 68) ve ülkenin büyüme performansını düşürme potansiyeli taşımaktadır (Aydın ve Çakmak, 2018: 4). Diğer yandan düşük gelirli ülkelerde yapılan sosyal koruma harcamaları aktif olmayan ve verimsiz kesime yapılan, mali olarak sürdürülemez bir tüketim transferi şeklinde düşünülebilmektedir. Bu durum ise kıt olan kamu kaynaklarının ekonomik büyüme sağlayacak üretken harcamalarından dişlanmasına neden olmaktadır (Devereux ve Sabates-Wheeler, 2004:1-2). Sosyal koruma harcamalarının siyasi amaçlar uğruna tercih edilmesi de etkinlik sorunu yaratabilecektir. Ayrica bu harcamalar bireylerin tasarruf düzeyini azaltabilmektedir. Bu durumda kamu tasarrufları eşit miktarda artmadıkça yatırım düzeyi ve mevcut sermaye birikiminde azalma ortaya çikabilecektir (Arjona vd., 2002: 9-10). Sosyal koruma harcamalarına yönelik eleştirilerden biri de bu harcamaların eşitlik verimlilik arasında ortaya çıkabilecek ödünleşimi tetikleyebileceğidir. $\mathrm{Bu}$ durum, yenilikçi ve girişimci kapasitenin kaybedilmesi riskini doğurabilmektedir (Ezcurra ve Rodríguez-Pose, 2009: 146).

\section{Literatür Özeti}

Çalışmanın literatür kısmında bir bütün olarak sosyal harcamalara odaklanan ve özelde sosyal harcama bileşenlerinin etkilerini araştıran literatürden seçilmiş çalışmalara yer verilmiştir. Literatürden edinilen genel kanı sosyal harcamalarının çoğunlukla ekonomik büyümeyi pozitif yönde etkilediği yönündedir. Bununla birlikte bazı ülke ve ülke grubu örneklerinde ya da sosyal harcamaların alt bileşenleri için yapılan çalışmalarda aksi sonuçlar tespit edildiği de gözlemlenmiştir.

Castles ve Dowrick (1990) 18 OECD ülkesi için yaptıkları çalışmalarında sosyal harcamaların 1960-1985 döneminde ekonomik büyüme üzerinde pozitif etkiye sahip olduğu sonucuna varmışlardır. Yazarlar benzer şekilde sosyal koruma harcamalarının da ekonomik büyümeyi olumlu yönde etkilediğini tespit etmişledir. $\mathrm{Bu}$ olumlu etki transferler yoluyla işgücünün yükselen moral ve risklere karşı güvenliğinin toplam faktör verimliliğini arttırması ile açıklanmıştır. Kelly (1997), 73 ülkede kamu harcamalarının ekonomik büyüme üzerindeki etkilerini 1970-1989 dönemi için araştırmıştır. Elde edilen sonuçlara göre yazar sosyal güvenlik harcamalarının ekonomik büyümeyi pozitif; eğitim ve sağlık harcamalarının ise negatif etkilediği sonucuna ulaşmıştır. Bununla birlikte tahmin edilen katsayılar istatiksel anlamlılık bakımından farklılık göstermektedir. Ülkelerin toplam eğitim harcamaları içeresindeki okul öncesi, ilk, orta ve yükseköğretim için yapılan harcama paylarının farklılaşması, sağlık sektöründe ise harcamaların önleyici sağlık hizmetlerinden ziyade tedavi edici alanlara yapılarak kaynak dağılımında etkisizliğin oluşması eğitim ve sağlık harcamalarının ekonomik büyümeyi negatif etkilemesinin arkasındaki muhtemel sebep olarak ortaya atılmıştır. Arjona vd. (2002), 21 OECD ülkesinde sosyal 
harcamaların ekonomik büyüme üzerindeki etkilerini 1970-1998 dönemi için araştırdıkları çalışmalarında toplam ve pasif sosyal harcamaların ekonomik büyümeyi negatif; aktif sosyal harcamaların pozitif etkilediği sonucuna ulaşmışlardır. $\mathrm{Bu}$ sonuçlara dayanarak sosyal harcama kompozisyonunun ekonomik büyüme sürecinde önem arz ettiği vurgulanmıştır. Kar ve Taban (2003) 1971-2000 döneminde eğitim ve sosyal güvenlik harcamalarının Türkiye'de ekonomik büyümeyi pozitif, sağlık harcamalarının ise negatif etkilediği tespit etmişlerdir. Baldacci vd. (2004) ve (2008) yaptıkları çalışmalarında sırasıyla 1975-2000 döneminde 120 ve 1971-2000 döneminde ise 118 gelişmekte olan ülkede sosyal harcamaların eğitim ve sağlık alanlarındaki sermaye birikimini pozitif etkilediğini, bu kanalla da ekonomik büyümeyi hızlandırdıklarını tespit etmişlerdir. Cho (2009), gelişmiş (OECD ülkeleri), yarı gelişmiş ve gelişmekte olan 85 ekonomide sosyal harcamaların ekonomik büyüme üzerindeki etkilerini araştırmıştır. 1990-2007 döneminin seçildiği çalışmada elde edilen sonuçlar sosyal harcamaların gelişmekte olan ülkelerde ekonomik büyümeyi pozitif, diğerlerinde ise negatif etkilediğini göstermektedir. Ezcurra ve Rodríguez-Pose (2009) 20 OECD ülkesinde yerel yönetimler tarafindan 1990-2005 döneminde yapılan sosyal koruma harcamaları ile toplam sosyal koruma harcamalarının ekonomik büyümeyi pozitif etkilediğini ve etkinin toplam sosyal koruma harcamalarında daha büyük olduğunu tespit etmişlerdir. Alam vd. (2010), 10 gelişmekte olan Asya ülkesi ve 1970-2015 dönemini kapsayan çalışmalarında sosyal harcamalar ile ekonomik büyüme arasında uzunlu dönemli ilişki tespit etmişler ve eğitim, sağlık ve sosyal koruma harcamalarının verimliliği arttırarak ekonomik büyümeyi olumlu etkilediği sonucuna ulaşmışlardır. Arısoy vd. (2010) Türkiye'de sosyal harcama ve alt bileşenleri olan sağlik, eğitim ve sosyal koruma harcamalarının 1960-2005 döneminde ekonomik büyüme üzerinde pozitif etkiye sahip olduklarını tespit etmişlerdir. Çalışmada Granger nedensellik testi sonuçlarına göre bu etkinin kısa dönemden ziyade uzun dönemde ortaya çıkacağı vurgulanmıştır. Furceri ve Zdzienicka (2012), 1980-2005 dönemini kapsayan çalışmalarında OECD ülkelerinde sosyal koruma harcamalarının ekonomik büyümeyi pozitif etkilediği sonucuna ulaşmışlardır. Ayrıca bulgulara göre sosyal koruma kapsamında yapılan sağlık hizmetleri ile işsizlik yardımlarının diğer koruma harcamalarından daha fazla etkiye sahip olduğunu vurgulanmıştır. Marinkow (2013) Güney Afrika'nın 9 bölgesi için yaptığ çalışmada 1995-2011 döneminde sosyal harcamalar ile ekonomik büyüme arsında uzun dönemli sinırlı bir ilişki olduğunu; kısa dönemde ise bu harcamaların ekonomik büyümeye katkı sağladığını ortaya koymuşlardır. Sosyal harcamaların personel harcamaları ve diğer harcamalar şeklinde sınıflandırıldığı model sonuçları ise diğer harcamaların ekonomik büyümeyi olumlu etkilediğini personel harcamalarının ise bir etkisinin olmadığını göstermektedir. Yazar bu sonucun Güney Afrika'da hükümetin ücret düşürmeye yönelik politikalarına bir dayanak oluşturabileceğini ileri sürmüştür. Musaba vd. (2013), 1980-2007 döneminde yapılan kamu harcamalarının sektörel dağılımı ile ekonomik büyüme arasındaki ilişkileri inceledikleri çalışmalarında 
eğitim, sağlık ve sosyal koruma harcamalarının Malawi'de ekonomik büyümeyi negatif etkilediği tespit etmişlerdir. Kolçak ve Kalabak (2017), Sosyal harcamaların ekonomik büyüme üzerindeki etkilerini 29 OECD ülkesinde 19982012 dönemi için araştırmışlardır. Elde edilen sonuçlar eğitim ve sağlık harcamalarının ekonomik büyümeyi pozitif; sosyal koruma harcamalarının ise negatif etkilediğini göstermektedir. Aydın (2019) 1980-2018 döneminde G7 ülkeleri özelinde yaptığı çalışmada sosyal harcamaların ekonomik büyümeyi pozitif etkilediği sonucuna ulaşmıştır. Ayrıca çalışmada sosyal harcamalardan ekonomik büyümeye doğru tek yönlü nedensellik tespit edilmiştir. Ersin ve Baş (2019) 1980-2016 dönemi ve Güney Avrupa refah modelinde yer alan 5 ülkeyi (Yunanistan, İspanya, Portekiz, İtalya ve Türkiye) kapsayan çalışmalarında sosyal harcamalar ile ekonomik büyüme arasında eşbütünleşme ilişkisi tespit etmişlerdir. Yazarlar ayrıca ekonomik büyümeden sosyal harcamalara doğru tek yönlü bir nedensellik olduğu sonucuna varmışlardır. Buna karşın sosyal harcamalardan ekonomik büyümeye doğru bir nedensellik tespit edilememiştir. Bu durum yazarlar tarafından sosyal harcamaların ekonomik büyümeyi negatif etkilediği şeklinde yorumlanmıştır. Polat (2020), sosyal harcamaların ekonomik büyüme üzerindeki etkilerini Türkiye için 1980-2016 döneminde araştırdığı çalışmasında değişkenler arasında uzun dönemli bir ilişki tespit edememiştir. Nedensellik analizinden elde edilen bulgular ise sosyal harcamalardan ekonomik büyümeye doğru tek yönlü bir nedensellik olduğunu göstermektedir.

\section{Veri Seti, Yöntem ve Bulgular}

Çalışmada İBBS'ye göre Türkiye'deki Düzey 1 bölgelerinde (12 Bölge $)^{3}$ kamu sosyal harcamaları ile bu harcamaların bileşenleri olan sağlık, eğitim ve sosyal koruma harcamalarının ekonomik büyüme üzerindeki kısa ve uzun dönemli etkileri panel veri analizi ile araştırılmıştır. 2004-2018 döneminin seçildiği çalışmada ekonomik büyümeyi temsilen bölgesel düzeyde 2009 fiyatlarıyla kişi başına düşen GSYH kullanılmış olup, veriler Türkiye İstatistik Kurumu (TÜİK) Bölgesel İstatistikler veri tabanından alınmıştır. Sosyal harcamalara ilişkin veriler Türkiye Cumhuriyeti Hazine ve Maliye Bakanlığı Muhasebat Genel Müdürlüğü Genel Yönetim Mali İstatistiklerinden derlenmiştir. Fonksiyonel bütçe sınıflandırması dikkate alınarak il düzeyinde sağlık, eğitim ve sosyal koruma harcama tutarları toplulaştırılmış ve Düzey 1 bölgeleri için sosyal harcamalar elde edilmiştir. Bu veriler bir sonraki aşamada deflate edilerek reel hale getirilmiştir. Çalışmada kullanılan verilere ait bilgiler ayrıca Tablo 1'de sunulmuştur. Ulusal hesaplara ait bölgesel verilerin 2004 yılından itibaren yayınlanması ve benzer şekilde iller itibariyle fonksiyonel bütçe harcamalarına 2004 yılı itibariyle ulaşılmış olması nedenleri ile çalışma 2004-2018 dönemi ile sınırlı tutulmuştur.

\footnotetext{
${ }^{3}$ Düzey 1 bölgeleri: İstanbul, Batı Marmara, Ege, Doğu Marmara, Batı Anadolu, Akdeniz, Orta Anadolu, Batı Karadeniz, Doğu Karadeniz, Kuzeydoğu Anadolu, Ortadoğu Anadolu, Güneydoğu Anadolu
} 
Tablo 1: Veri Seti

\begin{tabular}{|c|c|c|}
\hline Değișken & Tanım & Kaynak \\
\hline LGDP & Kişi Başına Düşen GSYH (2009 fiyatlarıyla, TL) & TüİK \\
\hline LSH & Kamu Sağlık Harcamaları (Reel, TL) & \multirow{4}{*}{$\begin{array}{l}\text { T.C. Hazine ve Maliye } \\
\text { Bakanlığı Muhasebat } \\
\text { Genel Müdürlüğü }\end{array}$} \\
\hline LEH & Kamu Eğitim Harcamaları (Reel, TL) & \\
\hline LSK & Kamu Sosyal Koruma Harcamaları (Reel, TL) & \\
\hline LSOSH & Kamu Sosyal Harcamalar (Reel, TL) & \\
\hline
\end{tabular}

Not: Değişken isimlerinin önündeki L harfi, logaritmik dönüşümün yapıldığını ifade etmektedir.

Sosyal harcamaların ekonomik büyüme üzerindeki etkilerini araştırmak için (1) ve (2) numaralı eşitliklerde gösterilen 2 ayrı panel veri modeli tahmin edilmiştir. Model (1)'de sosyal harcamalar bir bütün olarak ele alınmıştır. Model (2)'de ise sosyal harcamalar sağlık, eğitim ve sosyal koruma harcamaları şeklinde ayrıştırılmış ve her bir harcama kaleminin ekonomik büyüme üzerindeki etkileri ayrı ayrı incelenmiştir.

$$
\begin{aligned}
& L G D P_{i t}=\alpha_{0}+\alpha_{1} L_{S O S H_{i t}}+\varepsilon_{i t} \\
& L G D P_{i t}=\beta_{0}+\beta_{1} L S H_{i t}+\beta_{2} L E H_{i t}+\beta_{3} L S K_{i t}+u_{i t} \\
& \quad \mathrm{i}=1, \ldots ., 12 ; \mathrm{t}=1, \ldots .15 ; \mathrm{i}=\text { birim sayıs1; } \mathrm{t}=\text { zaman aralığ } 1
\end{aligned}
$$

Çalışmanın ampirik kısmı şu şekilde dizayn edilmiştir. Öncelikle CDLM testleri yardımıyla değişkenlerin yatay kesit bağımlılığı incelenmiştir. Ardından değişkenlerin durağanlık sınaması yapılmıştır. Durağanlıkların tespitinden sonra Ortalama Grup (MG) ve Havuzlanmış Ortalama Grup (PMG) tahmincileri ile uzun ve kısa dönemli katsayılar tespit edilmiş ve Hausman (1978) test sonucuna göre etkin tahmincinin ürettiği sonuçlar yorumlanmıştır.

Panel veri analizlerinde öncelikle birim kök testlerinin seçiminde belirleyici olan yatay kesit bağımlılığı araştırılmaktadır. Muhtemel bir yatay kesit bağımlılığının tespitinde, bu durumu dikkate alan birim kök testlerinin kullanılması gerekmektedir. Aksi durumda analiz sonuçlarından elde edilecek bulgular önemli ölçüde etkilenebilmektedir (Breusch ve Pagan, 1980; Pesaran 2004). Seriler arasındaki yatay kesit bağımlılığı literatürde sıklıkla başvurulan Berusch ve Pagan (1980) LM testi, Pesaran (2004) scaled LM ve Pesaran (2004) CD testleri yardımıyla araştırılmıştır. Hangi testin kullanılacağı ise zaman ve yatay kesit boyutlarınınım büyüklüğü arasındaki ilişkiye göre değişmektedir. Zaman boyutunun yatay kesit boyutundan büyük olduğunda $(\mathrm{T}>\mathrm{N})$ Berusch ve Pagan (1980) LM testi kullanılmakta iken Pesaran (2004) scaled LM testi N/T $\rightarrow \infty, N>T$ ve Pesaran (2004) $C D$ testi ise $\mathrm{T} \rightarrow \infty$ ya da $\mathrm{N} \rightarrow \infty, \mathrm{N}>\mathrm{T}, \mathrm{T}>\mathrm{N}$ durumlarında kullanılabilmektedir. Ayrıca Pesaran CD testi küçük örneklemlerde de etkin sonuçlar üretebilmektedir. Bu testlerde yatay kesit bağımlılığı olmadığını iddia eden boş hipotez sınanmaktadır. 
Tablo 2: Yatay Kesitsel Bağımlılık Test Sonuçları

\begin{tabular}{|c|c|c|c|c|c|c|}
\hline & \multicolumn{2}{|c|}{ Breusch-Pagan LM } & \multicolumn{2}{|c|}{ Pesaran scaled LM } & \multicolumn{2}{|c|}{ Pesaran CD } \\
\hline & $\begin{array}{c}\text { Test } \\
\text { İstatistiği }\end{array}$ & $\begin{array}{c}\text { Olasılık } \\
\text { Değeri }\end{array}$ & $\begin{array}{c}\text { Test } \\
\text { İstatistiği }\end{array}$ & $\begin{array}{c}\text { Olasılık } \\
\text { Değeri }\end{array}$ & $\begin{array}{c}\text { Test } \\
\text { İstatistiği }\end{array}$ & $\begin{array}{c}\text { Olasılık } \\
\text { Değeri }\end{array}$ \\
\hline LGDP & 987.055 & 0.000 & 80.167 & 0.000 & 31.417 & 0.000 \\
\hline LSH & 684.951 & 0.000 & 52.828 & 0.000 & 25.645 & 0.000 \\
\hline LEH & 975.477 & 0.000 & 78.115 & 0.000 & 31.2314 & 0.000 \\
\hline LSKH & 870.968 & 0.000 & 69.019 & 0.000 & 29.328 & 0.000 \\
\hline LSOSH & 973.321 & 0.000 & 77.927 & 0.000 & 31.197 & 0.000 \\
\hline Model 1 & 533.006 & 0.000 & 40.647 & 0.000 & 21.957 & 0.000 \\
\hline Model 2 & 952.700 & 0.000 & 77.177 & 0.000 & 30.859 & 0.000 \\
\hline
\end{tabular}

Çalışmada zaman boyutu yatay kesit boyutundan büyük olduğu için Berusch ve Pagan (1980) LM test sonuçlarına göre yatay kesit bağımlılığına karar verilebilir. Bununla birlikte yatay kesit bağımlılığına ilişkin tüm sonuçlar Tablo 2'de verilmiştir. Breusch-Pagan LM, Pesaran LM ve Pesaran CD testlerine göre çalışmada kullanılan hem tüm seriler hem de eşbütünleşme modelleri için yatay kesit bağımlılığının olmadığını iddia eden sıfır hipotezi \%1 anlamlılık düzeyinde reddedilmiştir. Diğer bir ifadeyle serilerde ve modellerde yatay kesitsel bağımlılık söz konudur. Buna göre birimlere ait serilerde meydan gelen şoklardan diğer birimlerde etkilenmektedir.

Seriler arasında yatay kesit bağımlılığının varlığı, serilerin durağanlık analizinde yatay kesit bağımlılığını dikkate alan ikinci nesil panel birim kök testlerinin kullanılmasını gerektirmektedir. Bu nedenle çalışmada yatay kesit bağımlılığını dikkate alan Pesaran (2007) tarafından geliştirilmiş yatay kesit genelleştirilmiş Dickey-Fuller (CADF) birim kök testi tercih edilmiştir. CADF denklemi, standart ADF denklemine gecikmeli yatay kesit ortalamaları ve yatay kesit ortalamalarının birinci farkları ilave edilerek elde edilmektedir.

Tablo 3: CADF Birim kök Testi Sonuçları

\begin{tabular}{llccc}
\hline \multicolumn{1}{c}{ Sabitli Model } & G & t-bar & Z [t-bar] & P-Değeri \\
\hline LGDP & 0 & -1.537 & 0.612 & 0.730 \\
ALGDP & 0 & -3.798 & -6.573 & 0.000 \\
LSH & 2 & -0.562 & 3.712 & 1.000 \\
DLSH & 0 & -3.631 & -6.041 & 0.000 \\
LEH & 0 & -2.390 & -2.097 & 0.018 \\
LSKH & 2 & -2.484 & -2.397 & 0.008 \\
LSOSH & 1 & -2.715 & -3.130 & 0.001 \\
\hline
\end{tabular}

Not: G, gecikme uzunluklarını ifade etmektedir. Maksimum gecikme uzunluğu 3 olarak belirlenmiş olup, gecikme uzunluklarının belirlenmesinde Akaike Bilgi Kriteri dikkate alınmıştır. Kritik değerler Pesaran (2007: 280) Tablo2b'den alınmış olup \%1, \%5 ve \%10 anlamlılık düzeyleri için sırasıyla, $-2.520,-2.280$ ve -2.160 'dır.

CADF birim kök test sonuçları Tablo 3'de verilmiştir. Buna göre LEH, LSKH ve LSOSH değişkenlerinin seviyelerinde, LGDP ve LSH değişsenlerinin ise birinci derece farkları alındıklarında durağan hale geldikleri tespit edilmiştir. 
Değişkenlerin farklı seviyelerde durağan $[\mathrm{I}(0)$ ve $\mathrm{I}(1)]$ olması nedeniyle kısa ve uzun dönem ilişkilerin incelenmesinde Gecikmesi Dağıtılmış Otoregresif (ARDL) model tercih edilmiştir. ARDL modelinin tahmininde Pesaran ve Smith (1995) tarafından geliştirilen MG ve Pesaran vd. (1999) tarafından geliştirilen PMG tahmincileri kullanılmıştır. MG tahmincisi uzun dönem katsayısını, her bir yatay kesit için tahmin edilen ARDL modelinden elde edilen uzun dönem katsayıların ortalamasını alarak hesaplamaktadır. Ayrıca bu yaklaşımda uzun dönem katsayıları birimlere göre değişmektedir. Diğer bir ifadeyle her bir yatay kesit birim için uzun dönem katsayısının hesaplanmasına imkan vermektedir. PMG tahmincisi ise uzun dönem katsayıların birimler arasında değişmediğini yani homojen olduklarını varsaymakta, buna karşın kısa dönem katsayıların birimden birime değişmesine izin vermektedir. Küçük örneklem ve dengesiz panellerin için tutarlı sonuçlar sağlamaktadır (Topal, 2019: 10). Bu tahmincilerden hangisinin uygun tahminci olduğuna başka bir deyişle uzun dönem katsayılarının homojen ya da heterojen olup olmadığına ise Hausman (1978) testi ile karar verilmektedir (Pesaran vd., 1999: 11)

PMG ve MG tahmin bulgularına yer verilen Tablo 4'de görüleceği üzere Hausman test istatistiği sonucuna göre uzun dönem katsayıları homojen olup birimden birime değişmemektedir. Buna göre PMG tahmincisi daha etkin ve tutarlı sonuçlar üretmektedir. PMG tahmin sonuçlarına göre LSOSH değişkeninin katsayısı pozitif ve istatistiksel olarak anlamlıdır. Diğer bir ifadeyle sosyal harcamalarda meydana gelen artışlar uzun dönemde ekonomik büyümeyi hızlandırmaktadır. Dolayısıyla sosyal harcamaların kamu harcamaları içerisindeki payının artması uzun dönemde büyüme için önemli bir politika tercihi olabilecektir.

Tablo 4: ARDL PMG ve MG Tahmin Sonuçları

\begin{tabular}{lcccccc}
\hline \multicolumn{1}{c}{ Model 1 } & \multicolumn{3}{c}{ PMG } & \multicolumn{2}{c}{ MG } & \\
\hline \multicolumn{1}{c}{ Uzun dönem } & Katsay1 & Standart Hata & T İstatistiği & Katsay1 & Standart Hata & T İstatistiği \\
\hline LSOSH & 1.366 & 0.087 & $15.77^{\mathrm{a}}$ & 1.110 & 0.500 & $2.22^{\mathrm{b}}$ \\
\hline \multicolumn{1}{c}{ Kisa dönem } & & & & & \\
\hline Hata Düzeltme Terimi & -0.067 & 0.033 & $-2.07^{\mathrm{b}}$ & -0.063 & 0.040 & -1.57 \\
$\Delta$ LSOSH & -0.475 & 0.097 & $-4.90^{\mathrm{a}}$ & -0.481 & 0.099 & $-4.88^{\mathrm{a}}$ \\
Sabit & -0.572 & 0.354 & -1.62 & -0.507 & 0.503 & -1.01 \\
\hline Hausman Testi & & $\mathbf{0 . 2 6}(\mathbf{0 . 6 1 3})$ & &
\end{tabular}

Not: a ve b, ilgili katsayının \%1 ve \%5 seviyesinde anlamlı olduğunu ifade etmektedir. Parantez içi olasılık değerini göstermektedir.

Kısa dönemli sonuçlar incelendiğinde hata düzeltme katsayısının teorik beklentilerle uyumlu olarak negatif ve $\% 5$ düzeyinde istatistiksel olarak anlamlı olduğu görülmektedir. Bu sonuç değişkenler arasında uzun dönemli bir ilişki olduğunu desteklemektedir. Hata düzeltme katsayısı kısa dönem sapmalarının bir sonraki dönemde dengeye gelme hızını göstermektedir. Bir dönemde oluşan dengesizliklerin yaklaşık \%7'si bir sonraki dönem giderilecektir. Elde edilen sonuç kısa dönemdeki dengesizliklerin yavaş bir şekilde uzun dönem dengesine 
yaklaştığını göstermektedir. Diğer yandan sosyal harcamalara ait kısa dönem katsayıs1 \%5 önem düzeyinde istatistiksel olarak anlamlı ve ekonomik büyümeyi negatif etkilemektedir.

Tablo 5: ARDL PMG ve MG Tahmin Sonuçları

\begin{tabular}{|c|c|c|c|c|c|c|}
\hline \multirow{2}{*}{ Model 2} & \multicolumn{3}{|c|}{ PMG } & \multicolumn{3}{|c|}{ MG } \\
\hline & Katsay 1 & Standart Hata & T İstatistiği & Katsay 1 & Standart Hata & T İstatistiği \\
\hline \multicolumn{7}{|l|}{ Uzun dönem } \\
\hline LSH & 0.508 & 0.124 & $4.09^{\mathrm{a}}$ & 7.634 & 7.940 & 0.96 \\
\hline LEH & 1.506 & 0.162 & $9.30^{\mathrm{a}}$ & 7.970 & 7.262 & 1.10 \\
\hline LSKH & -0.181 & 0.045 & $-4.02^{a}$ & -9.302 & 9.586 & -0.97 \\
\hline \multicolumn{7}{|l|}{ Kısa dönem } \\
\hline Hata Düzeltme Terimi & -0.168 & 0.039 & $-4.32^{a}$ & -0.145 & 0.049 & $-2.94^{a}$ \\
\hline$\Delta \mathrm{LSH}$ & -0.048 & 0.018 & $-2.61^{a}$ & -0.063 & 0.038 & $-1.65^{c}$ \\
\hline$\triangle \mathrm{LEE}$ & -0.554 & 0.122 & $-4.56^{a}$ & -0.553 & 0.118 & $-4.71^{a}$ \\
\hline$\triangle \mathrm{LSKH}$ & -0.162 & 0.038 & $-4.30^{a}$ & -0.180 & 0.046 & $-3.88^{a}$ \\
\hline Sabit & -2.768 & 0.691 & $-4.01^{\mathrm{a}}$ & -2.472 & 1.157 & -1.63 \\
\hline
\end{tabular}

Hausman Testi

$5.76(0.124)$

Not: a ve c, ilgili katsayının \%1 ve \%10 seviyesinde anlamlı olduğunu ifade etmektedir. Parantez içi olasılık değerini göstermektedir.

Sosyal harcamaların ekonomik büyüme üzerindeki etkilerini daha detaylı görebilmek için sosyal harcama bileşenlerinin kullanıldığı Model 2 tahmin edilmiştir. Sonuçlar Tablo 5'de görülmektedir. Burada da Hausman test istatistiği PMG tahmincisinin tutarlı ve etkin olduğuna işaret etmektedir. Uzun dönem sonuçlarına göre değişkenlere ait katsayıların tümü \%1 anlamlılık düzeyinde istatistiksel olarak anlamlıdır. LSH ve LEH değişkenleri ekonomik büyümeyi pozitif etkilerken, LSKH değişkeni ise negatif etkilemektedir. Ĕgitim ve sağlik harcamalarına ait katsayılar incelendiğinde eğitim harcamalarının ekonomik büyüme üzerinde sağlı harcamalarına nazaran daha belirleyici olduğu görülmektedir. Sosyal koruma harcamalarının negatif etkisi ise nispi olarak sınırlıdır. Bu bağlamda kamu, sosyal harcamalar arasında sağlık ve özellikle eğitim harcamaları lehine bir tercih yaparak uzun dönemde ekonomik büyümeyi teşvik edebilir.

Kısa dönemde tüm katsayılar uzun dönemde olduğu gibi \%1 anlamlılık düzeyinde istatistiksel olarak anlamlıdır. Sosyal harcamayı oluşturan her üç değișkende kısa dönemde ekonomik büyümeyi negatif etkilemektedir. Hata düzeltme terimi katsayısı istatistiksel olarak anlamlı ve negatif işaretlidir. Dolaysıyla değişkenler arasında uzun dönemli ilişkinin varlığı doğrulanmaktadır. Katsayının değeri bir dönemdeki dengeden sapmanın yaklaşık \%17'sinin bir sonraki dönem giderileceğini ve 6 dönem sonra uzun dönem dengesine ulaşacağını ifade etmektedir.

\section{Sonuç}

Kamu sektörü bütçesiyle harcamalar yaparak ekonomide aktif bir rol üstlenmektedir. $\mathrm{Bu}$ harcamalar ile ekonomik büyümeyi sürdürmek, işsizliği azaltmak, yoksulluğu önlemek, beşeri sermaye birikimine katkıda bulunmak, 
verimliliği arttırmak, bölgesel eşitsizliği gidermek vb. şeklinde sıralanabilecek çok geniş bir yelpazede amaçlar gütmekte ve bu yolla toplumsal refahı yükseltmeyi hedeflemektedir. Kamunun ulaşmak istediği hedefler için yaptığ 1 harcamalardan biri de eğitim, sağlık ve sosyal koruma harcamalarından oluşan sosyal harcamalardır. Bu bağlamda 2004-2018 dönemini kapsayan bu çalışmada, sosyal harcamaların ve bileşenlerinin ekonomi büyüme üzerindeki etkileri Türkiye Düzey 1 bölgeleri için panel veri analizi ile ayrı ayrı araştırılmıştır.

Çalışmada elde edilen sosyal harcamaların bütün olarak ekonomik büyümeyi uzun dönemde olumlu yönde etkilediğini göstermektedir. Bu bulgu hareketle sosyal harcamamaların büyüklüğünün ekonomik büyüme için önemli olduğunu göstermektedir. Diğer yandan sosyal harcama bileşenlerinin etkileri ayrıştırıldığında eğitim harcamalılarının uzun dönemde ekonomik büyüme üzerinde önemli bir belirleyici olduğunu göstermektedir. Ayrıca sağlık harcamaları da ekonomik büyümeyi pozitif etkilemektedir. Ancak aynı sonuç sosyal koruma harcamaları için söz konusu değildir. Analiz sonuçları sosyal koruma harcamaların ekonomik büyümeyi uzun dönemde negatif etkilediğini göstermektedir. Bununla birlikte eğitim ve sağlık harcamaları ile karşılaştırıldığında etkisi sınırlı kalmaktadır. Kısa dönemde ise sosyal harcamalar ekonomik büyümeyi olumsuz etkilemektedir. Kısa dönemde ekonomide harcamabüyüme ilişkisinin zayıf olması; uzun dönemde ise eğitim ve sağlık harcamalarının beşeri sermaye ve verimlilik artışına yol açması ve sosyal koruma harcamalarının çalışma isteğini ve verimliliği azaltması sonuçların arkasındaki muhtemel nedenler olarak ileri sürülebilir. Sonuçlardan hareketle sosyal harcamaların büyüklüğünün yanı sıra kompozisyonun da ekonomik büyüme için önemli olduğu görülmektedir. Dolayısıyla kamu harcamalarının sosyal harcamalar lehine planlanması ve benzer şekilde sosyal harcamaların kompozisyonunun da sağlık ve özellikle eğitim lehine, sosyal koruma harcamaları aleyhine değiştirilmesi uzun dönemde ekonomik büyümeye katkı sağlayacaktır.

\section{Kaynakça}

Alam, S., Sultana, A. ve Butt, M. S. (2010). Does Social Expenditures Promote Economic Growth? A Multivariate Panel Cointegration Analysis for Asian Countries. European Journal of Social Sciences, 14(1), 44-54.

Altınay, A. T. (2018). Sosyal Koruma Harcamalarının Yapay Zeka Değerlendirme Tekniklerinden Girdap Optimizasyon Algoritması Aracılığ Maliyet Analizi. Journal of Accounting, Finance and Auditing Studies, 4(2), 106125 .

Arjona, R., Ladaique, M. ve Pearson, M. (2003). Social Protection and Growth. OECD Economic Studies, 2002(2), 7-45.

Arısoy, İ., Ünlükaplan, İ. ve Ergen, Z. (2010). Sosyal Harcamalar ve İktisadi Büyüme İlişkisi: Türkiye Ekonomisinde 1960-2005 Dönemine Yönelik Bir Dinamik Analiz. Maliye Dergisi, 158, 398-421. 
Aydın, M. K. ve Çakmak, E. E. (2018). Sosyal Devlet ve Türkiye. Bilgi Sosyal Bilimler Dergisi, 20(2), 1-12.

Aydın , F. F. (2019). G7 Ülkelerinde Sosyal Harcamaların Ekonomik Büyüme Üzerine Etkisi. Iğdır Üniversitesi Sosyal Bilimler Dergisi, Ek Sayı, 91-107.

Baldacci, E., Clements, B., Gupta, S. ve Cui, Q. (2004). Social Spending, Human Capital, and Growth in Developing Countries: Implications for Achieving the MDGs. IMF Working Paper, WP/04/217.

Baldacci, E., Clements, B., Gupta, S. ve Cui, Q. (2008). Social Spending, Human Capital, and Growth in Developing Countries. World Development, 36(8), 1317-1341.

Blankenau, W. F. ve Simpson, N. B. (2004). Public Education Expenditures and Growth. Journal of Development Economics, 73(2), 583-605.

Bloom, D. E., Mahal, A., Rosenberg, L. ve Sevilla, J. (2000). Opening Presentation: Social Protection and Conditional Cash Transfers. S. W. Handayani ve C. Burkley (Ed.), Social Assistance and Conditional Cash Transfers içinde (12-22. ss.). Mandaluyong City, Philippines: Asian Development Bank.

Breusch, T. S. ve Pagan, A. R. (1980). The Lagrange Multiplier Test and Its Applications to Model Specification in Econometrics. The Review of Economic Studies, 47(1), 239-253.

Burgess, R., ve Stern, N. (1991). Social Security in Developing Countries: What, Why, Who and How?. E. Ahmad, J. Drèze, J. Hills ve A. Sen (Ed.), Social Security in Developing Countries içinde (41-80. ss.). Clarendon, United Kingdom: Oxford University Press.

Castles, F. G. ve Dowrick, S. (1990). The impact of Government Spending Levels on Medium-Term Economic Growth in the OECD, 1960-85. Journal of Theoretical Politics, 2(2), 173-204.

Cho, W. (2009). Empirical Analysis of the Relation between Social Spending and Economic Growth: Developing Countries and OECD Members. Yayımlanmamış Doktora Tezi, Graduate School of Public Administration Seoul National University, Korea.

Devereux, S. ve Sabates-Wheeler, R. (2004). Transformative Social Protection. IDS Working Paper, 232. Brighton: Institute of Development Studies.

Ersin, İ. ve Baş, H. (2019). Güney Avrupa Refah Ülkelerinde Sosyal Harcamalar ve Ekonomik Büyüme Arasındaki İlişkinin İncelenmesi. Sosyal Güvenlik Dergisi, 193-213.

Eurostat. (2016). European System of Integrated Social Protection Statistics Manual and User Guidelines. Luxembourg: Publications Office of the European Union. 
Ezcurra, R. ve Rodríguez-Pose, A. (2011). Decentralization of Social Protection Expenditure and Economic Growth in the OECD. Publius, 41(1), 146157.

Furceri, D. ve Zdzienicka, A. (2012). The Effects of Social Spending on Economic Activity: Empirical Evidence from a Panel of OECD Countries. Fiscal Studies, 33(1), 129-152.

Görkem, H. (2019). Türkiye'de Kamu Sosyal Koruma Harcamaları Kapsamında Engellilere Yönelik Harcamalar: Karşılaştırmalı Bir Değerlendirme. Social Sciences Studies Journal, 5(36), 2855-2868.

Hausman, J. A. (1978). Specification Tests in Econometrics. Econometrica, 46(6), 1251-1271.

ILO. (2017). World Social Protection Report 2017-19. Universal social protection to achieve the Sustainable Development Goals. https://www.ilo.org/wcmsp5/groups/public/---dgreports/---dcomm/--publ/documents/publication/wcms_604882.pdf (Erişim: 10.05.2020).

IMF. (2019). A Strategy for IMF Engagement on Social Spending. https://www.imf.org/en/Publications/Policy-Papers/Issues/2019/06/10/A-Strategyfor-IMF-Engagement-on-Social-Spending-46975 (Erişim: 10.05.2020).

Kar, M. ve Taban, S. (2003). Kamu Harcama Çeşitlerinin Ekonomik Büyüme Üzerine Etkisi. Ankara Üniversitesi SBF Dergisi, 58(3), 1. https://doi.org/10.1501/sbfder_0000001652

Kelly, T. (1997). Public expenditures and growth. Journal of Development Studies, 34(1), 60-84. https://doi.org/10.1080/00220389708422503

Koç, Ö. E. (2019). Sosyal Devlet ve Sosyal Bütçe Perspektifinden Türkiye'de Sosyal Harcamalar. N. Koç (Ed.), Güncel Sosyal ve Mali Sorunlara Yönelik Seçme Yazılar içinde (53-76. ss.). Ankara: Siyasal Kitapevi.

Kolçak, M. ve Kalabak, A. Y. (2017). Kısa Dönemde Sosyal Harcamalar ile Ekonomik Büyüme Arasındaki İlişki, 29/28 OECD Ülkesi için Panel Veri Analizi (1998-2012). Gazi Universitesi Iktisadi ve Idari Bilimler Fakultesi Dergisi, 19(1), $1-19$.

Marinkov, M. (2013). The Effects of Social Spending on Economic Activity in South African Provinces. Technical Report: Submission for the Division of Revenue 2014/2015.

Musaba, E., Chilonda, P. ve Matchaya, G. (2013). Impact of Government Sectoral Expenditure on Economic Growth in Malawi, 1980-2007. Journal of Economics and Sustainable Development, 4(2), 71-79.

OECD. (2012). Social Spending During the Crisis, Social Expenditure (SOCX)

Data

Update

2012. 
http://www.oecd.org/els/soc/OECD2012SocialSpendingDuringTheCrisis8pages.p df (Erişim: 10.08.2020).

Pesaran, M. H. (2004). General Diagnostic Tests for Cross Section Dependence in Panels. Cambridge Working Papers in Economics, No. 0435.

Pesaran, M. H. (2007). A Simple Panel Unit Root Test in the Presence of Cross-Section Dependence. Journal of Applied Econometrics, 22(2), 265-312.

Pesaran, M. H. ve Smith, R. (1995). Estimating Long-Run Relationships from Dynamic Heterogeneous Panels. Journal of Econometrics, 68(1), 79-113.

Pesaran, M. H., Shin, Y. ve Smith, R. P. (1999). Pooled Mean Group Estimation of Dynamic Heterogeneous Panels. Journal of the American statistical Association, 94(446), 621-634.

Polat, E. (2020). Sosyal Harcamalar Ekonomik Büyümeyi Etkiliyor Mu? TürkiyeÖrneği. 3. Sektör Sosyal Ekonomi Dergisi, 55(1), 268-281.

Sawhill, I. V. (1988). Poverty in the U. S.: Why is it so Persistent? Journal of Economic Literature, 26(3), 1073-1119.

Solmaz, E. ve Avc1, M. (2017). Yoksullukla Mücadelede Sosyal Koruma Harcamaları: Avrupa Birliği Ülkeleri Üzerine Bir İnceleme. Muğla Sitkı Koçman Üniversitesi İktisadi ve İdari Bilimler Fakültesi Ekonomi ve Yönetim Araştırmaları Dergisi, 6(1), 46-73.

Topal, M. H. (2019) An Analysis of the Relationship between Tax Structure and Gross Domestic Product in European Transition Economies. Journal of European Theoretical and Applied Studies, 7(2), 1-19. 